\title{
Lactoferrin Enhances Hydroxyl Radical Production by Human Neutrophils, Neutrophil Particulate Fractions, and an Enzymatic Generating System
}

\author{
Daniel R. Ambruso and Richard B. Johnston, Jr., Departments of Pediatrics, \\ National Jewish Hospital and Research Center, University of Colorado \\ School of Medicine, and Belle Bonfils Memorial Blood Center, \\ Denver, Colorado 80262
}

\begin{abstract}
A в S T R A C T During phagocytosis, neutrophils take oxygen from the surrounding medium and convert it to superoxide anion $\left(\mathrm{O}_{2}^{-}\right)$and hydrogen peroxide $\left(\mathrm{H}_{2} \mathrm{O}_{2}\right)$. Hydroxyl radical $(\cdot \mathrm{OH})$, a particularly potent oxidant, is believed to be produced by interaction between $\mathrm{O}_{2}^{-}$and $\mathrm{H}_{2} \mathrm{O}_{2}$ in the presence of iron, according to the Haber-Weiss reactions. Production of $\cdot \mathrm{OH}$ by whole human neutrophils, by particulate fractions from human neutrophils disrupted after stimulation, and by a xanthine oxidase system was measured by conversion of $\alpha$-keto- $\gamma$-methiol butyric acid to ethylene. $\mathrm{FeCl}_{3}$ or ferric EDTA enhanced ethylene production in all three systems by $155-406 \%$ of base line at a concentration of 50-100 $\mu \mathrm{M}$. Iron-saturated human milk lactoferrin, $100 \mathrm{nM}$, increased ethylene generation by $127-296 \%$; and purified human neutrophil lactoferrin, $10 \mathrm{nM}$, enhanced ethylene production by $167-369 \%$. Thus, iron bound to lactoferrin was $\sim 5,000$ times more effective in producing an enhancement in ethylene generation than iron derived from $\mathrm{FeCl}_{3}$ or ferric EDTA. $\mathrm{O}_{2}^{-}$and $\mathrm{H}_{2} \mathrm{O}_{2}$ were required for ethylene production in the presence of lactoferrin, since superoxide dismutase inhibited ethylene formation in the three systems by $76-97 \%$ and catalase inhibited by $76-98 \%$. Ethylene production in the presence of lactoferrin was inhibited by the $\cdot \mathrm{OH}$ scavengers mannitol, benzoate, and thiourea by $43-85,45-94$, and 76-96\%, respectively. Thus, most of the ethylene production could be attributed to oxidation of $\alpha$-keto- $\gamma$-methiol butyric acid by $\cdot \mathrm{OH}$. The ability of neutrophil lactoferrin to provide iron efficiently to the oxygen radical-generating systems is compatible with a role for lactoferrin as regu-
\end{abstract}

This work was presented in part at the annual meeting of the American Society for Clinical Investigation, May 121980 in Washington, D. C., and was published in Abstract form in 1980. Clin Res. 28: 490A.

Received for publication 23 April 1980 and in revised form 6 October 1980 . lator of $\cdot \mathrm{OH}$ production. As such, lactoferrin may be an important component in the microbicidal activity of neutrophils.

\section{INTRODUCTION}

Neutrophils that are actively phagocytosing consume oxygen and convert it to superoxide anion $\left(\mathrm{O}_{2}^{-}\right)$and hydrogen peroxide $\left(\mathrm{H}_{2} \mathrm{O}_{2}\right)$ (1). In chemical systems, these two oxygen compounds are believed to interact to form hydroxyl radical $(\cdot \mathrm{OH})$, one of the most potent oxidants known (2), as summarized by the following reaction:

$$
\mathrm{O}_{2}^{-}+\mathrm{H}_{2} \mathrm{O}_{2} \rightarrow \cdot \mathrm{OH}+\mathrm{OH}^{-}+\mathrm{O}_{2}
$$

Although this reaction is thermodynamically possible, it probably occurs too slowly to be of relevance in biological systems (3). In chemical systems, iron can increase the rate constant of this interaction to about $1,000 \mathrm{M}^{-1} \mathrm{~s}^{-1}$, a level at which this reaction could have biologic significance (3). This interaction, originally described by Haber and Weiss (4), can be summarized in the following equations:

$$
\begin{gathered}
\mathrm{O}_{2}^{-}+\mathrm{Fe}^{+++} \rightarrow \mathrm{O}_{2}+\mathrm{Fe}^{++} \\
\mathrm{Fe}^{++}+\mathrm{H}_{2} \mathrm{O}_{2} \rightarrow \mathrm{Fe}^{+++}+\cdot \mathrm{OH}+\mathrm{OH}^{-}
\end{gathered}
$$

Evidence for the generation of $\cdot \mathrm{OH}$ by actively phagocytosing cells has been presented $(5-10)$. Previous observations indicated that phagocytic killing of bacteria by human neutrophils could be inhibited by superoxide dismutase (SOD), ${ }^{1}$ which removes $\mathrm{O}_{2}^{-}$, and by catalase, which removes $\mathrm{H}_{2} \mathrm{O}_{2}$ (5). This sug-

\footnotetext{
${ }^{1}$ Abbreviations used in this paper: BSA, bovine serum albumin; KMB, $\alpha$-keto- $\gamma$-methiol butyric acid: KRP-D, KrebsRingers phosphate buffer with dextrose; LF, lactoferrin; PBS, phosphate buffered saline; PMA, phorbol myrisate acetate; $R_{f}$, relative migration index; SOD, superoxide dismutase.
} 
gested that the important bactericidal species was neither $\mathrm{O}_{2}^{-}$nor $\mathrm{H}_{2} \mathrm{O}_{2}$, but rather, a product of their interaction. Inhibition of phagocytic bactericidal activity by benzoate and mannitol, agents believed to scavenge $\cdot \mathrm{OH}(2)$, suggested that this product might be $\cdot \mathrm{OH}$ (5). More direct evidence for $\cdot \mathrm{OH}$ formation during phagocytosis has been provided by studies based on its interaction with methional or $\alpha$-keto- $\gamma$ methiol butyric acid (KMB) to form ethylene (6-8), with dimethyl sulfoxide to produce methane (9), and with 5,5-dimethyl-1-pyrroline- $N$-oxide to form a specific adduct identified by electron spin resonance (10). In addition, a 27,000 g particulate fraction of activated human neutrophils has been shown to produce ethylene (11).

In the studies reported here we have demonstrated that lactoferrin (LF), an iron-binding protein found in specific granules of neutrophils, enhances $\cdot \mathrm{OH}$ generation by human neutrophils, by particulate fractions of neutrophils, and by a xanthine oxidase system that generates oxygen radicals.

\section{METHODS}

Reagents. SOD, bovine serum albumin (BSA), KMB, NADH, NADPH, EDTA, catalase, xanthine oxidase, mannitol, ferritin, and transferrin were obtained from Sigma Chemical Co., St. Louis, Mo. Sodium benzoate and EDTA (J. T. Baker Chemical Co., Phillipsburg, N. J.), N-ethylmaleimide (Eastman Kodak Co., Rochester, N. Y.), phorbol myristate acetate (PMA, Consolidated Midland Corp., Brewster, N. Y.), human milk LF (Calbiochem-Behring Corp., La Jolla, Calif.), anhydrous ferric chloride $\left(\mathrm{FeCl}_{3}\right.$, Mallinkrodt Inc., St. Louis, Mo.), and desferrioxamine (Ciba Pharmaceutical Co., Div., Ciba-Geigy Corp., Summit, N. J.) were obtained commercially. Acetaldehyde (Matheson, Coleman \& Bell, Norwood, Ohio) was distilled and stored at $-20^{\circ} \mathrm{C}$ for use. Catalase was filtered over a column of Bio-Gel A-1.5 m (BioRad Laboratories, Richmond, Calif.) to remove SOD and other impurities (5). SOD and catalase were heat-inactivated by autoclaving stock solutions at $121^{\circ} \mathrm{C}$ for $30 \mathrm{~min}$. The resultant solutions were lightly sonicated to separate aggregates and dialyzed against the appropriate buffer overnight to remove free metals, especially iron.

Neutrophils. Neutrophils were separated from the blood of normal human volunteers and of two patients with chronic granulomatous disease in $98 \%$ purity by dextran sedimentation and Ficoll-Hypague centrifugation (5). The withdrawal of blood for the purposes of this study was approved by the Utilization Review Committee of National Jewish Hospital and Research Center. Contaminating erythrocytes were removed by hypotonic lysis. In some experiments, neutrophils were prepared in $85-90 \%$ purity by using only dextran sedimentation and hypotonic lysis. There was no difference between these two preparations in the amount of ethylene generated or in the inhibition by $\mathrm{OH}$ scavengers, and the data obtained with either was combined.

Particulate fraction. Particulate fractions were prepared from human neutrophils as described $(12,13)$. Cells were stimulated by incubation with opsonized zymosan $(5 \mathrm{mg} / \mathrm{ml})$ or PMA $(100 \mathrm{ng} / \mathrm{ml})$ for $3 \mathrm{~min}$ at $37^{\circ} \mathrm{C}$. Activation was stopped by addition of an equal vol of $0.68 \mathrm{M}$ sucrose, and the neutrophils were disrupted by sonication or homogenization.
This preparation was centrifuged at $100 \mathrm{~g}$ to remove cell debris, and the resultant supernate was centrifuged at $27,000 \mathrm{~g}$ for $30 \mathrm{~min}$. The $27,000 \mathrm{~g}$ pellet was resuspended in $0.34 \mathrm{M}$ sucrose and its protein content was determined (14). No difference was observed in ethylene production by particulate fractions made from cells treated with PMA or with opsonized zymosan.

The amount of LF and myeloperoxidase (MPO) in the particulate fraction was quantitated by radioimmunoassay (15), using antibody donated by Dr. Barbara Bentwood, and by interaction with o-dianisidine (15), respectively. In the presence of $0.1 \%$ Triton X-100, MPO activity was $57 \pm 3$ $\mathrm{U} / \mu \mathrm{g}$ protein (mean $\pm \mathrm{SEM}, n=11$ ); however, in the absence of Triton X-100 $<5 \%$ of this activity was measured. Therefore, the MPO present in the particulate fraction appears largely unavailable for interaction with oxygen radicals. In the presence of Triton X-100 LF concentration was $210 \pm 10$ $\mu \mathrm{g} / \mathrm{mg}$ protein (mean $\pm \mathrm{SEM}, n=3$ ).

Preparation of $L F$. Neutrophil LF was purified from neutrophils isolated in $98 \%$ purity by a modification of described techniques $(16,17)$. Cells were diluted in $0.1 \mathrm{M}$ sodium phosphate buffer, $\mathrm{pH} 8.0$, with $1 \mathrm{M} \mathrm{NaCl}$, to a concentration of $1.5 \times 10^{8} / \mathrm{ml}$ and then disrupted by freezing and thawing six times using an ethanol-dry ice bath. This preparation was centrifuged at $100 \mathrm{~g}$ for $15 \mathrm{~min}$, and the supernate was centrifuged at $125,000 \mathrm{~g}$ for $120 \mathrm{~min}$. The resultant supernate was dialyzed against $0.01 \mathrm{M}$ phosphate buffer, $\mathrm{pH}$ 7.0. This preparation was placed on a column of DEAE-Sephadex A-25 (Pharmacia Fine Chemicals, Inc., Piscataway, N. J.) and washed with buffer until the effluent was free of protein measured by absorbance at $280 \mathrm{~nm}$. Neutrophil LF was eluted from this column with a salt gradient of $0-0.8 \mathrm{M} \mathrm{NaCl}$ in $0.01 \mathrm{M}$ phosphate buffer, pH 7.0. Neutrophil LF was identified by radioimmunoassay (15), and the fractions containing neutrophil LF were filtered over Bio-Gel P-150 or Sephadex G-200. The amount of neutrophil LF in the final preparation was determined by radioimmunoassay (15). Both neutrophil and milk LF exhibited no myeloperoxidase activity as measured by interaction with $o$-dianisidine (15).

The purity of LF was assessed by sodium dodecyl sulfatepolyacrylamide gel electrophoresis (18). In neutrophil LF preparations a majority of the protein was in one band with a relative migration index $\left(R_{f}\right)$ of 0.27 . There was also a faint band of $R_{f}$ value of 0.31 . In milk LF preparations the majority of protein was in a band with $R_{f} 0.28$, and there were minor protein bands at 0.35 and 0.93 . When neutrophil LF and milk LF were mixed before electrophoresis, there were bands with $R_{f}$ values of $0.29,0.36$, and 0.96 , respectively. Most of the protein was at $R_{f} 0.29$.

An affinity column for LF was made by cyanogen bromide coupling of rabbit anti-human LF (Bio-Rad, Laboratories, Richmond, Calif.) to Sepharose 6B (19). Neutrophil LF preparation was passed over the column and washed with phosphate- buffered saline (PBS), $\mathrm{pH}$ 7.4. The LF was eluted with $3.5 \mathrm{M}$ sodium thiocyanate (J. T. Baker Chemical Co.) in $0.01 \mathrm{M}$ tris buffer, $\mathrm{pH}$ 7.2. A small protein peak appeared in the PBS wash that produced no enhancement of ethylene production in the xanthine oxidase system. The protein eluted with thiocyanate, after dialysis against PBS and suspension to the volume of the original preparation, produced enhancement in ethylene production comparable to that achieved by the original preparation. In addition, this latter protein peak produced a single band on sodium dodecyl sulfate-polyacrylamide gel electrophoresis. Thus, it appeared that neutrophil LF, not the minor contaminant of the preparation, is responsible for the enhanced ethylene production described here. 
Milk LF and neutrophil LF were saturated with iron by the technique of Broxmeyer et al. (20). After addition of enough $10 \mathrm{mM}$ ferric citrate to saturate LF, the mixture was allowed to sit at room temperature for $30 \mathrm{~min}$, then dialyzed overnight at $4^{\circ} \mathrm{C}$ in PBS, with frequent changes in dialysis buffer. Unsaturated LF was dialysed against PBS as control. Iron saturation of LF was determined qualitatively by examining change in absorbance at $450 \mathrm{~nm}(21)$. Iron-poor LF from either source exhibited no absorbance at this wavelength, whereas saturation of LF with iron resulted in a measurable increase in absorbance. The extent of saturation was determined quantitatively by labeling studies that measured the amount of ${ }^{59} \mathrm{Fe}$ bound to a known amount of protein. These studies indicated that both LF preparations were fully saturated with iron (neutrophil LF $117 \pm 16 \%$ saturated; milk LF $122 \pm 15 \%$ saturated; mean \pm SEM, $n=3$ ). Saturation of LF was performed by several other techniques using $\mathrm{FeCl}_{3}$ and trisodium nitrilotriacetate $(22)$ or excess citrate (23). These exhibited similar results to previously mentioned techniques in spectrophotometric studies and enhancement of ethylene generation in the xanthine oxidase system. Iron-poor transferrin was made iron-saturated by this same technique (20). Desferrioxamine was saturated by incubation with an equimolar quantity of $\mathrm{FeCl}_{3}$. Ferric EDTA was prepared as described (24).

Measurement of ethylene production. Generation of $\cdot \mathrm{OH}$ by neutrophils, particulate fractions and a xanthine oxidase system was measured by its interaction with KMB to form ethylene. For whole cells, the $10-\mathrm{ml}$ glass reaction vial contained $1 \mathrm{mM}$ KMB and $2.5 \times 10^{6}$ neutrophils in Krebs-Ringers phosphate buffer pH 7.34 with $20 \mathrm{mg} / \mathrm{ml}$ dextrose (KRP-D) to make a $2.5-\mathrm{ml}$ reaction vol. The vial was stoppered, and $1.0 \mathrm{mg}$ of opsonized zymosan was introduced. Vials were incubated at $37^{\circ} \mathrm{C}$ for $60 \mathrm{~min}$ in a shaking water bath. Unstimulated (resting) neutrophils or stimulated neutrophils from patients with chronic granulomatous disease generated $0-13 \%$ as much ethylene as activated neutrophils. Maximal ethylene generation was highly dependent on cell concentration, the optimum being $1 \times 10^{6} \mathrm{cells} / \mathrm{ml}$. At this concentration ethylene generation had a linear, direct relationship with cell number.

The amount of ethylene produced by neutrophils was also quantitated in iron-depleted solutions. Distilled water was extracted repeatedly with dithizone (Sigma Chemical Co.) dissolved in carbon tetrachloride (25) until no color change was noted. Excess carbon tetrachloride was removed by boiling. Phosphate buffers were made with this water and then re-extracted with dithizone. Lysis solutions and KRP-D were prepared from iron-free water and phosphate buffers. Cells were isolated with the iron-depleted solutions in glassware washed with $1 \mathrm{M}$ nitric acid, then rinsed with iron-depleted distilled water. No difference in the amount of ethylene generated was observed between cells isolated in regular solutions compared to those isolated in iron-depleted media either resting or after stimulation with opsonized zymosan.

The $27,000 \mathrm{~g}$ pellet of disrupted human neutrophils has previously been shown to produce oxygen radicals (11-13). For particulate fractions, the vials contained $0.25 \mathrm{mg}$ particulate fraction, $10 \mathrm{mM}$ KMB, and KRP-D to a vol of $2.5 \mathrm{ml}$. Production of ethylene required the addition of $0.1 \mathrm{mM}$ $\mathrm{NADPH}$, and samples were incubated for $60 \mathrm{~min}$ at $37^{\circ} \mathrm{C}$. Fractions from resting cells or from stimulated cells of two patients with chronic granulomatous disease produced $<1 \%$ as much ethylene as did fractions from stimulated normal cells. Generation of ethylene in response to varying concentrations of NADPH exhibited a plateau between 0.1 and $0.2 \mathrm{mM}$ NADPH. When $0.1 \mathrm{mM}$ NADH was used in this system, the amount of ethylene generated was $<1 \%$ of that produced by $0.1 \mathrm{mM}$ NADPH, but ethylene production could easily be detected at NADH concentrations of $0.2 \mathrm{mM}$ or higher. Ethylene generation was also dependent on the concentration of particulate fraction, the optimum being 0.1 $\mathrm{mg}$ protein $/ \mathrm{ml}$. Ethylene production varied linearly with amount of particulate fraction at this concentration.

For the chemical generating system, $100 \mathrm{mU}$ of xanthine oxidase was added to a stoppered reaction vial containing $0.1 \mathrm{mM}$ EDTA, $1 \mathrm{mM} \mathrm{KMB}, 5 \mathrm{mM}$ acetaldehyde, and 0.05 $\mathrm{M}$ phosphate buffer, $\mathrm{pH} 7.8$, to a vol of $2.0 \mathrm{ml}$. Ethylene production in the xanthine oxidase system was measured after incubation for $15 \mathrm{~min}$ at $37^{\circ} \mathrm{C}$.

All reactions were terminated by addition of $1 \mathrm{mM} \mathrm{N}$ ethylmaleimide and immersion in an ice bath. Ethylene released into the vapor phase was quantitated by gas chromatography (26). In each experiment ethylene production was determined as the difference between that generated by the complete system, including $\mathrm{FeCl}_{3}$, ferric EDTA, or LF, and that generated by the system minus the activator (opsonized zymosan, NADPH, or xanthine oxidase). In all experiments, the activatorless systems produced $\leq 10 \%$ of the ethylene generated by the complete systems. Assays for ethylene were performed in duplicate or triplicate.

Specificity of KMB-ethylene system. Production of $\cdot \mathrm{OH}$ by phagocytic cells has been measured by techniques based on the principle that $\cdot \mathrm{OH}$ interacts with a chemical compound to produce a second chemical species that can be quantitated $(6-11)$. The specificity of each method depends upon the specificity of the interaction of $\cdot \mathrm{OH}$ with the compound. Since the specificity of such interactions is not absolute, further characterization of these detection systems according to the model of the Haber-Weiss reactions (Eqs. 2 and 3) should depend on demonstrating a requirement for both $\mathrm{O}_{2}^{-}$and $\mathrm{H}_{2} \mathrm{O}_{2}$ by demonstrating inhibition of the expected product by SOD and catalase. In addition, generation of this product should be inhibited by scavengers of . OH such as mannitol, benzoate, and thiourea, which have a higher rate constant for interaction with $\cdot \mathrm{OH}$ than does the detecting compound $(2,27,28)$.

The system described here for measuring $\cdot \mathrm{OH}$ depends on its interaction with KMB to form ethylene. However, it is possible that other radicals interact with $\mathrm{KMB} . \mathrm{O}_{2}^{-}$reacts weakly with methional (29), and perhaps it may react with $\mathrm{KMB}$, a related compound. Klebanoff and Rosen have raised the possibility that ethylene production from KMB in the MPO $\mathrm{H}_{2} \mathrm{O}_{2}$-halide system may be the result of singlet oxygen, not $\cdot \mathrm{OH}(8)$. With all three generating systems described here, however, ethylene generation was dependent on the presence of $\mathrm{O}_{2}^{-}$and $\mathrm{H}_{2} \mathrm{O}_{2}$, since SOD $(12 \mu \mathrm{g} / \mathrm{ml})$ inhibited $87-93 \%$ and catalase $(250 \mu \mathrm{g} / \mathrm{ml}$ ) inhibited $78-88 \%$ (numbers represent the means of three to five experiments with each inhibitor in each of the three systems). The effect of heat-inactivated enzymes was $4-24 \%$ inhibition for SOD and $0-17 \%$ inhibition for catalase. The nonspecific protein effect of BSA $(250 \mu \mathrm{g} / \mathrm{ml})$ caused $8-22 \%$ inhibition. Specific $\cdot \mathrm{OH}$ scavengers, $50 \mathrm{mM}$ mannitol, 20-50 mM benzoate, and $1 \mathrm{mM}$ thiourea $(27,28)$ inhibited ethylene production by $50-72$ $53-82$, and $74-95 \%$, respectively. These scavengers at these concentrations did not inhibit production of $\mathrm{O}_{2}^{-}$by phagocytosing neutrophils, measured as described (5). Urea, which is structurally similar to thiourea but does not react with - $\mathrm{OH}(28)$, did not inhibit ethylene production. Thus, in all three systems, the majority of ethylene production from KMB was related to $\cdot \mathrm{OH}$ or a powerful oxidant (e.g., $\cdot \mathrm{OR}$ ) with characteristics similar or identical to $\cdot \mathrm{OH}$. For the sake of simplicity, we use the term $\cdot \mathrm{OH}$ for this oxidant in this paper. 


\section{RESULTS}

In the three oxygen radical-generating systems, LF purified from human milk or neutrophils, when saturated with iron, enhances ethylene production (Table I). Unsaturated LF from either source showed no stimulatory effect. Enhancement of ethylene production by LF was a concentration-dependent phenomenon (Fig. 1). The optimal concentration in particulate fractions and xanthine oxidase systems was $100-200 \mathrm{nM}$ for milk LF (Fig. 1A and B). Because each molecule of LF binds two molecules of iron $(16,21)$, this concentration delivered 200-400 $\mathrm{nM}$ iron to the reaction mixture. The optimal concentration of neutrophil LF in both systems was $10 \mathrm{nM}$ (Fig. 1C and D), which delivered $20 \mathrm{nM}$ iron to the reaction. Unsaturated LF from either source showed slight inhibition of ethylene production at higher concentrations (Fig. 1). Iron-saturated LF from milk, or neutrophils at 100 and $10 \mathrm{nM}$ concentrations, had no effect in all three systems on $\mathrm{O}_{2}^{-}$ production, measured as SOD-inhibitable reduction of cytochrome $c$ (5) (two or three experiments in the presence and absence of the activator for the system).

As predicted by the Haber-Weiss reactions, iron enhanced ethylene production in the oxygen radicalgenerating systems. Results with $\mathrm{FeCl}_{3}$ and ferric EDTA are shown in Table I. This was a concentration- dependent phenomenon, optimal enhancement being achieved with $50 \mu \mathrm{M}$ for neutrophils and $100 \mu \mathrm{M}$ for particulate fractions and the xanthine oxidase system (data not shown). $\mathrm{FeCl}_{3}$ and ferric EDTA at a concentration of $200 \mathrm{nM}$ had no effect on ethylene production (Table I). Thus, the concentration of $\mathrm{FeCl}_{3}$ or ferric EDTA required to give an optimal increase in ethylene production, an increase comparable to that achieved with LF, was 500-5,000 times the iron concentration delivered to the generating system by LF. In addition, the greater efficiency of iron-saturated LF at enhancing ethylene production was not due to a nonspecific iron-protein interaction since ethylene generation was not altered in any of the systems when $200 \mathrm{nM} \mathrm{FeCl}_{3}$ and $100 \mathrm{nM}$ BSA were added together to the reaction (data not shown). The difference in results with $\mathrm{FeCl}_{3}$ and ferric EDTA may be related to the availability of iron for the production of $\cdot \mathrm{OH}$. At neutral $\mathrm{pH}, \mathrm{FeCl}_{3}$ is hydrolyzed to form insoluble hydroxides; ferric EDTA does not form insoluble complexes (30). Enhancement to a similar extent was shown in all three systems with ferrous iron (ferrous sulfate), as predicted by the Haber-Weiss reactions.

The effect of other iron-containing compounds on ethylene formation was studied with the particulate fractions and xanthine oxidase system (Table II). In both systems iron-saturated transferrin increased

TABLE I

Effect of Iron and LF on Ethylene Generation by Neutrophils, Particulate Fractions, and a Xanthine Oxidase System

\begin{tabular}{|c|c|c|c|}
\hline \multirow[b]{2}{*}{ Iron or lactoferrin added } & \multicolumn{3}{|c|}{ Ethylene generation* } \\
\hline & Neutrophils & $\begin{array}{l}\text { Particulate } \\
\text { fraction }\end{array}$ & $\begin{array}{l}\text { Xanthine } \\
\text { oxidase } \\
\text { system }\end{array}$ \\
\hline & \multicolumn{3}{|c|}{$\%$} \\
\hline None & 100 & 100 & 100 \\
\hline Milk LF, iron-poor (100 nM) & $84 \pm 22(3)$ & $82 \pm 13(3)$ & $76 \pm 5$ \\
\hline Milk LF, iron-saturated (100 nM) & $127 \pm 8 \quad(3) \ddagger$ & $155 \pm 6 \quad(3) \S$ & $296 \pm 33(3) t$ \\
\hline Neutrophil LF, iron-poor (10 nM) & $87 \pm 13(3)$ & $89 \pm 4$ & $120 \pm 6$ \\
\hline Neutrophil LF, iron-saturated (10 nM) & $167 \pm 6(3) \S$ & $265 \pm 21(3) \S$ & $369 \pm 38(3) \neq$ \\
\hline $\mathrm{FeCl}_{3}(200 \mathrm{nM})$ & $100 \pm 2$ & $103 \pm 7 \quad(3)$ & $105 \pm 3$ \\
\hline $\mathrm{FeCl}_{3}(50-100 \mu \mathrm{M})$ & $155 \pm 10(6) \ddagger$ & $230 \pm 35(3) \ddagger$ & $238 \pm 6 \quad(3) \S$ \\
\hline Ferric-EDTA (200 nM) & $96 \pm 12(3)$ & $91 \pm 11(4)$ & $102 \pm 2$ \\
\hline Ferric-EDTA $(50-100 \mu \mathrm{M})$ & $300 \pm 17(3) \S$ & $406 \pm 53(3) \ddagger$ & $314 \pm 25(3) \S$ \\
\hline
\end{tabular}

\footnotetext{
* Ethylene generation in the presence of iron or LF is expressed as a percentage of the ethylene produced in the same experiment by the generating system alone. Baseline values for the three generating systems were: neutrophils, $232.7 \pm 44.8 \mathrm{pmol} / 2.5$ $\times 10^{6}$ cells per $60 \mathrm{~min}$ (mean $\pm \mathrm{SEM}, n=27$ ); particulate fractions, $12.3 \pm 1.3 \mathrm{pmol} / \mathrm{mg}$ protein per $\min , n=23$; and xanthine oxidase, $1.65 \pm 0.12 \mathrm{nmol} / 15 \mathrm{~min}, n=22$. The percentage values represent mean $\pm S E M$ and the number of experiments is in parentheses.

\$ Value is significantly different from that obtained in paired experiments with mixtures lacking iron or LF, $P<0.05$ by paired $t$ test.

$\S$ Significance at $P<0.01$ by paired $t$ test.
} 

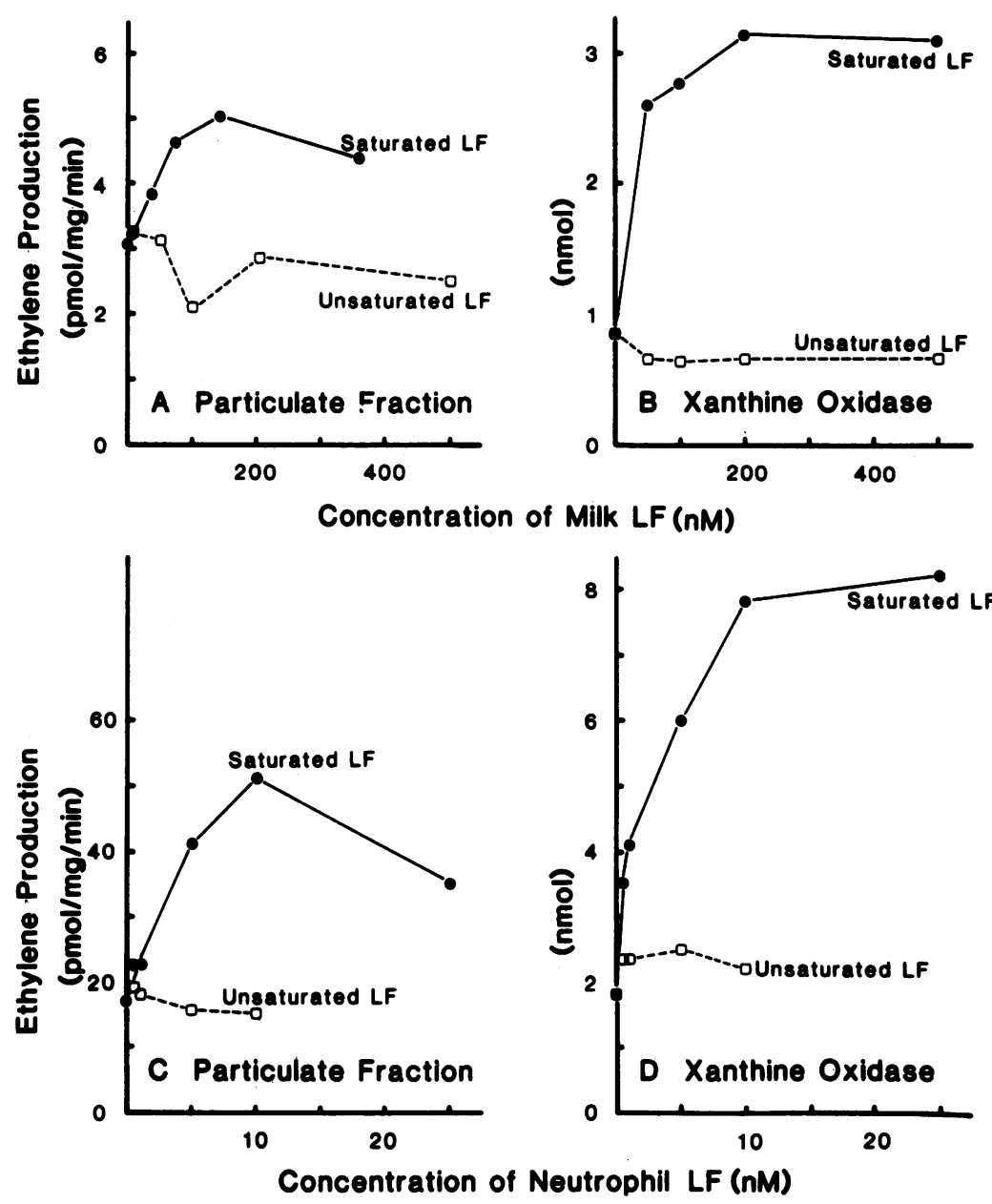

FIGURE 1 Effect of varying concentrations of LF on ethylene generation. (A) Ethylene produced by particulate fraction, effect of milk LF. (B) Ethylene produced by xanthine oxidase system, effect of milk LF. (C) Particulate fraction, neutrophil LF. (D) Xanthine oxidase system, neutrophil LF. All experiments were performed as described in Methods. The results shown are those of representative experiments of three performed with each combination (A-D).

ethylene production significantly. With particulate fractions, unsaturated transferrin, ferritin, and ironsaturated desferrioxamine, a nonprotein siderophore with high specific affinity for iron (31), had no significant effect on increasing ethylene generation. In the xanthine oxidase system, ferritin and iron-saturated desferrioxamine exhibited a slight but significant enhancement of ethylene generation. Ferritin, which contains a variable amount of iron (32), provided the reaction mixtures with $100-300 \mathrm{mM}$ iron, and desferrioxamine provided $100 \mathrm{nM}$ iron.

The effect of scavengers of oxygen metabolites on the ethylene production obtained with LF is shown in Table III. SOD inhibited 96-97\% with neutrophils, $90-91 \%$ with particulate fractions, and $76-87 \%$ with xanthine oxidase. Catalase reduced LF-enhanced ethylene production by $76-86 \%$ with neutrophils,
$84-96 \%$ in particulate fractions and by $88-98 \%$ in the xanthine oxidase system. BSA showed minimal inhibition (0-20\%). With the three $\cdot \mathrm{OH}$-generating systems, inhibition with $\cdot \mathrm{OH}$ scavengers was $43-85 \%$ with mannitol, 45-94\% with benzoate and 76-96\% with thiourea. Urea had no appreciable inhibitory effect. Thus, the majority of the LF-enhanced ethylene production could be related to $\cdot \mathrm{OH}$ generation.

\section{DISCUSSION}

The role of iron in enhancing production of $\cdot \mathrm{OH}$ was first suggested by Haber and Weiss (4), and has been subsequently confirmed in chemical generating systems $(3,33,34)$. In our studies, ferrous or ferric iron added to aqueous solution as simple salts or complexed with EDTA increased $\cdot \mathrm{OH}$ formation, meas- 
TABLE II

Effect of Iron-Containing Compounds on Ethylene Production by Particulate Fractions and Xanthine Oxidase System*

\begin{tabular}{llll}
\hline & \multicolumn{3}{c}{ Ethylene generation } \\
\cline { 2 - 4 } \multicolumn{1}{c}{ Compound added } & $\begin{array}{c}\text { Particulate } \\
\text { fraction }\end{array}$ & $\begin{array}{c}\text { Xanthine } \\
\text { oxidase }\end{array}$ \\
\hline & \multicolumn{3}{c}{$\%$} \\
$\begin{array}{l}\text { Transferrin, iron-poor } \\
\quad(100 \mathrm{nM})\end{array}$ & $98 \pm 1 \quad(3)$ & $110 \pm 4 \quad(4)$ \\
$\begin{array}{l}\text { Transferrin, iron-saturated } \\
(100 \mathrm{nM})\end{array}$ & $259 \pm 59(3) \ddagger$ & $293 \pm 22(4) \S$ \\
$\begin{array}{l}\text { Ferritin }(100 \mathrm{nM}) \\
\text { Desferrioxamine, iron- } \\
\text { saturated }(100 \mathrm{nM})\end{array}$ & $106 \pm 13(3)$ & $142 \pm 8 \quad(4) \S$ \\
\hline
\end{tabular}

* Ethylene generation is expressed as a percentage of the ethylene produced in the same experiment by the generating system (particulate fraction or xanthine oxidase) alone. Values represent mean $\pm \mathrm{SEM}$; the number of experiments is in parentheses.

$\$$ Value is significantly different from that obtained in paired experiments with mixtures lacking the added compound, $P<0.05$ by paired $t$ test.

$\S$ Significance at $P<0.01$ by paired $t$ test.

ured as ethylene production, by three systems capable of converting oxygen to $\mathrm{O}_{2}^{-}$and other metabolites. The enhancement of ethylene generation by iron suggested the possibility that an iron-containing or iron- binding protein in the neutrophil might increase the formation of $\cdot \mathrm{OH}$ during phagocytosis. Our studies showed that iron-saturated LF from human colostrum and human neutrophils enhanced ethylene production by neutrophils, neutrophil particulate fractions, and a chemical generating system. This enhancement required $0.2-0.02 \%$ as much iron as that produced by $\mathrm{FeCl}_{3}$ or ferric EDTA. Unsaturated LF had no significant effect on ethylene generation. BSA and $\mathrm{FeCl}_{3}$ together produced no enhancement, indicating that the effect of LF was not related to nonspecific protein interaction with iron. Both $\mathrm{O}_{2}^{-}$and $\mathrm{H}_{2} \mathrm{O}_{2}$ were necessary for this LF-associated effect, and most of the enhanced ethylene generated was inhibited by thiourea, mannitol, or benzoate and, as such, was attributable to $\cdot \mathrm{OH}$. Enhancement of ethylene production by milk and neutrophil LF was less with intact neutrophils and the particulate fractions than with the xanthine oxidase system, perhaps because of the LF released by the intact cells during phagocytosis and because of the presence of LF in the particulate fraction.

LF, an iron-binding protein found in exocrine excretions and neutrophils leukocytes of mammals, belongs to the siderophilin class of proteins and shares many of its physicochemical properties with transferrin (35). LF has a mol wt of $\sim 90,000$, and each molecule of LF binds two molecules of iron with high affinity $(16,21,36)$. In contrast to transferrin, this affinity remains high at low $\mathrm{pH}(36)$, and these two proteins are immunologically distinct (37). Transferrin, when

TABLE III

Inhibition of Ethylene Formation by Scavengers of Oxygen Metabolites in the Presence of LF*

\begin{tabular}{|c|c|c|c|c|c|c|}
\hline \multirow[b]{2}{*}{ Inhibitor } & \multicolumn{2}{|c|}{ Neutrophils } & \multicolumn{2}{|c|}{ Particulate fractions } & \multicolumn{2}{|c|}{ Xanthine oxidase system } \\
\hline & $\begin{array}{l}\text { Iron-saturated } \\
\text { milk LF }\end{array}$ & $\begin{array}{l}\text { Iron-saturated } \\
\text { neutrophil LF }\end{array}$ & $\begin{array}{l}\text { Iron-saturated } \\
\text { milk LF }\end{array}$ & $\begin{array}{l}\text { Iron-saturated } \\
\text { neutrophil LF }\end{array}$ & $\begin{array}{l}\text { Iron-saturated } \\
\text { milk LF }\end{array}$ & $\begin{array}{l}\text { Iron-saturated } \\
\text { neutrophil LF }\end{array}$ \\
\hline & \multicolumn{6}{|c|}{ \% inhibition } \\
\hline $\operatorname{SOD}(12 \mu \mathrm{g} / \mathrm{ml})$ & $96 \pm 2(3)$ & $97 \pm 2 \quad(3)$ & $91 \pm 8$ & $90 \pm 1 \quad(3)$ & $76 \pm 1 \quad(3)$ & $87 \pm 5(3)$ \\
\hline Heat-inactivated SOD & & & & & & \\
\hline$(12 \mu \mathrm{g} / \mathrm{ml})$ & $14 \pm 3(3)$ & $16 \pm 6 \quad(3)$ & $11 \pm 6 \quad(2)$ & $8 \pm 3 \quad(3)$ & $5 \pm 5$ & $13 \pm 9(3)$ \\
\hline Catalase $(250 \mu \mathrm{g} / \mathrm{ml})$ & $86 \pm 2(3)$ & $76 \pm 6 \quad(3)$ & $96 \pm 7 \quad(3)$ & $84 \pm 2$ & $88 \pm 1$ & $98 \pm 2(3)$ \\
\hline \multicolumn{7}{|l|}{ Heat-inactivated catalase } \\
\hline$(250 \mu \mathrm{g} / \mathrm{ml})$ & $16 \pm 5(3)$ & $18 \pm 10(3)$ & $3 \pm 3$ & $1 \pm 1$ & $10 \pm 10(3)$ & $13 \pm 4(4)$ \\
\hline BSA $(250 \mu \mathrm{g} / \mathrm{ml})$ & $0(3)$ & $0(3)$ & $7 \pm 5 \quad(2)$ & $20 \pm 14(3)$ & $6 \pm 6$ & $2 \pm 2(3)$ \\
\hline Mannitol (50 mM) & $43 \pm 5(3)$ & $50 \pm 3 \quad(3)$ & $69 \pm 19(3)$ & NDt & $80 \pm 3 \quad(3)$ & ND \\
\hline Mannitol (100 mM) & $63 \pm 7(3)$ & $70 \pm 2$ & $72 \pm 16(3)$ & $65 \pm 15(3)$ & $80 \pm 2 \quad(2)$ & $85 \pm 1(3)$ \\
\hline Benzoate $(20 \mathrm{mM})$ & $45 \pm 3(3)$ & $48 \pm 7 \quad(3)$ & $56 \pm 9$ & ND & $85 \pm 2 \quad(3)$ & ND \\
\hline Benzoate $(50 \mathrm{mM})$ & $67 \pm 6(3)$ & $73 \pm 1 \quad(3)$ & $64 \pm 14(3)$ & $59 \pm 11(2)$ & $91 \pm 2$ & $94 \pm 1(3)$ \\
\hline Thiourea $(1 \mathrm{mM})$ & $82 \pm 2(3)$ & $77 \pm 3$ & $96 \pm 2 \quad(3)$ & $92 \pm 1 \quad(3)$ & $76 \pm 1$ & $79 \pm 2(3)$ \\
\hline Urea $(1 \mathrm{mM})$ & $3 \pm 3(3)$ & $8 \pm 7$ & $9 \pm 2$ & $0(3)$ & $4 \pm 2$ & $9 \pm 5(3)$ \\
\hline
\end{tabular}

* The effect of the inhibitors on ethylene formation by the three systems is shown. The results are expressed as percentage by which the inhibitor reduced ethylene formation in paired experiments done in duplicate or triplicate. Values represent mean $\pm \mathrm{SEM}$; the number of experiments is shown in parentheses. Milk LF was present at a concentration of $100 \mathrm{nM}$ and neutrophil $\mathrm{LF}$ at a concentration of $5 \mathrm{nM}$.

$\$ \mathrm{ND}$, not done. 
saturated with iron, promoted an increased production of ethylene by particulate fractions and the xanthine oxidase system; iron-poor transferrin did not. This is not surprising, in light of the similarities between lactoferrin and transferrin. Other iron-containing compounds, ferritin and iron-saturated desferrioxamine, enhanced ethylene production relatively ineffectively, suggesting that chemically bound iron is not, by itself, sufficient to increase $\cdot \mathrm{OH}$ production. The structure of LF and transferrin, when saturated with iron, may permit more effective presentation of iron to the $\cdot \mathrm{OH}$ generating system.

In the hematopoietic system, LF is found almost exclusively in the specific granules of neutrophils $(22,38-40)$. It is released both into the phagolysosome and outside the cell during phagocytosis (40). Previous reports have suggested that LF may play a role in neutrophil bactericidal activity. Several patients have been described who had repeated infections and whose neutrophils lacked LF or specific granules (41-45). Wang-Iverson et al. have shown a defect in bactericidal activity at high bacteria-to-cell ratios with neutrophils depleted of specific granules and LF by pretreatment with PMA (46).

In addition to an antimicrobial function, LF may play a role in tissue damage related to inflammation. LF is found in abundance in areas of inflammatory reaction such as exudates of arthritic joints (47) and bronchial secretions of patients with chronic pulmonary inflammation (48). Oxygen radicals have been implicated in the pathogenesis of inflammation (49). Thus, LF, released together with $\mathrm{O}_{2}^{-}$and $\mathrm{H}_{2} \mathrm{O}_{2}$ at an inflammatory site, could promote formation of the particularly potent oxidant, $\cdot \mathrm{OH}$, with a resultant tissue injury.

Enhancement of $\cdot \mathrm{OH}$ production in our systems depended on saturation of the LF with iron. Although it has been reported that LF isolated from neutrophils is relatively iron-poor, the isolation process may leach iron from the protein. In fact, we found that partially purified LF, when saturated with ${ }^{59} \mathrm{Fe}$, lost this iron during simple purification procedures. However, if LF were poorly iron-saturated when released into the phagocytic vacuole, it might obtain iron from the internalized milieu or from the microbe itself. Chang showed that ${ }^{131}$ I-labeled albumin added to a phagocytic reaction medium was taken up by phagocytes during ingestion of starch particles (50). Thus, substances in the environment might be internalized during phagocytosis and serve as sources of iron for LF. One particularly interesting possibility in this regard would be transferrin, which, in contrast to LF, releases bound iron readily as the $\mathrm{pH}$ drops to levels easily achieved in the phagocytic vacuole ( $\mathrm{pH} 5-6)$ (51). In preliminary experiments, there was a change in the absorbance spectrum for LF and transfer of ${ }^{59} \mathrm{Fe}$ to LF detectable after dialysis of iron-saturated transferrin (in- side dialysis bag) against iron-free LF (outside). There was a significant transfer of iron to LF, especially at lower $\mathrm{pH}(\mathrm{pH} 5)$. In similar experiments using Escherichia coli as a source of iron (inside the bag), transfer of iron to unsaturated LF was also documented. Repine et al. (52) have reported that bactericidal activity of an $\mathrm{H}_{2} \mathrm{O}_{2}$ system was related to iron from the bacteria and was inhibited by scavengers of $\cdot \mathrm{OH}$, supporting the hypothesis that iron may be obtained from the phagocytosed microorganism.

On the basis of the reports supporting a role for specific granules in microbicidal activity of the neutrophil, the abundance of LF in specific granules (39, 40,42 ), and our data showing that LF enhances $\cdot \mathrm{OH}$ production we would hypothesize that LF could play an important role as regulator of $\cdot \mathrm{OH}$ production during phagocytosis. During ingestion, $\mathrm{O}_{2}^{-}$and $\mathrm{H}_{2} \mathrm{O}_{2}$ are released into the vacuole with the captured microorganisms, and the $\mathrm{pH}$ within the vacuole decreases. Fusion of specific granules with the phagolysosome results in release of $L F$ into the phagocytic vacuole. The released LF might contain iron or, especially at low $\mathrm{pH}$, iron might be obtained from the internalized milieu of the phagocytic vacuole or the microbe itself. Localization of iron-containing LF in the vacuole with the microbe would result in efficient generation of $\cdot \mathrm{OH}$ and, presumably, more effective antimicrobial activity.

\section{ACKNOWLEDGMENTS}

The authors thank Doctors Michael J. Pabst, Linda C. McPhail, Henry Rosen, and Philip Aisen for constructive suggestions, Dr. Masataka Sasada for myeloperoxidase assays, Drs. Barbara J. Bentwood and Peter M. Henson for providing antibody to LF, Dr. Steve Wallner for supplying ${ }^{59} \mathrm{Fe}$, Mrs. Shirley Dougherty for her technical assistance, and Mss. Marie Blackman and Beverly Polt for help in preparing the manuscript.

This research was supported by grant AI 14148 from the National Institute of Allergy and Infectious Diseases; by grant BRSG RR-05357 awarded by the Biomedical Research Grant Program, Division of Research Resources, National Institutes of Health; and by the Stacey M. True Memorial Fund.

\section{REFERENCES}

1. Babior, B. M. 1978. Oxygen-dependent microbial killing by phagocytes. N. Engl. J. Med. 298: 659-668.

2. Neta, P., and L. M. Dorfman. 1968. Pulse radiolysis studies XIII. Rate constants for the reaction of hydroxyl radical with aromatic compounds in aqueous solutions. Adv. Chem. Sci. 81: 222-230.

3. McCord, J. M., and E. D. Day. 1978. Superoxide-dependent production of hydroxyl radical catalyzed by iron-EDTA complex. FEBS (Fed. Eur. Biochem. Soc.) Lett. 86: 139-142.

4. Haber, F., and J. Weiss. 1934. The catalytic decomposition of hydrogen peroxide by iron salts. Proc. R. Soc. Edinb. Sect. (Math. Phys. Sci.) 147: 332-351.

5. Johnston, R. B., Jr., B. B. Keele, Jr., H. P. Misra, J. E. Lehmeyer, L. S. Webb, R. L. Baehner, and K. V. 
Rajagopalan. 1975. The role of superoxide anion generation in phagocytic bactericidal activity. Studies with normal and chronic granulomatous disease leukocytes. J. Clin. Invest. 55: 1357-1372.

6. Tauber, A. I., and B. M. Babior. 1977. Evidence for hydroxyl radical production by human neutrophils. $J$. Clin. Invest. 60: 374-379.

7. Weiss, S. J., P. K. Rustagi, and A. F. LoBuglio. 1978. Human granulocyte generation of hydroxyl radical. J. Exp. Med. 147: 316-323.

8. Klebanoff, S. J., and H. Rosen. 1978. Ethylene formation by polymorphonuclear leukocytes. Role of myeloperoxidase. J. Exp. Med. 148: 490-506.

9. Repine, J. E., J. W. Eaton, M. W. Anders, J. R. Hoidal, and R. B. Fox. 1979. Generation of hydroxyl radical by enzymes, chemicals, and human phagocytes in vitro. Detection with the anti-inflammatory agent, dimethylsulfoxide. J. Clin. Invest. 64: 1642-1651.

10. Rosen, H., and S. J. Klebanoff. 1979. Hydroxyl radical generation by polymorphonuclear leukocytes measured by electron spin resonance spectroscopy. J. Clin. Invest. 64: 1725-1729.

11. Tauber, A. I., T. G. Gabig, and B. M. Babior. 1979. Evidence for production of oxidizing radicals by the particulate $\mathrm{O}_{2}^{-}$forming system from human neutrophils. Blood. 53: 666-676.

12. McPhail, L. C., L. R. DeChatelet, and R. B. Johnston, Jr. 1979. Generation of chemiluminescence by a particulate fraction isolated from human neutrophils. Analysis of molecular events. J. Clin. Invest. 63: 648-655.

13. McPhail, L. C., D. R. Ambruso, M. J. Pabst, and R. B. Johnston, Jr. 1979. Generation of oxygen metabolites by phagocytic cells: studies with a subcellular fraction of human neutrophils. In Biochemical and Clinical Aspects of Oxygen. W. S. Caughey, editor. Academic Press, Inc., New York. 709-724

14. Lowry, O. H., N. J. Rosebrough, A. L. Farr, and R. J. Randall. 1951. Protein measurement with the Folin phenol reagent. J. Biol. Chem. 193: 265-275.

15. Bentwood, B. J., and P. M. Henson. 1980. The sequential release of granule constituents from human neutrophils. J. Immunol. 124: 855-862.

16. Masson, P. L., J. F. Heremans, and E. Schonne. 1969. Lactoferrin, an iron-binding protein in neutrophilic leukocytes. J. Exp. Med. 130: 643-657.

17. Mendelsohn, N., R. R. Eger, H. E. Broxmeyer, and M. A. S. Moore. 1978. Isolation of granulocyte colony inhibitory factor derived from human polymorphonuclear leukocytes. Biochim. Biophys. Acta. 533: 238-247.

18. Weber, K., and M. Osborn. 1969. The reliability of molecular weight determinations by dodecylsulfatepolyacrilamide gel electrophoresis. J. Biol. Chem. 244: 4406-4412.

19. March, S. C., I. Parikh, and P. Cuatrecasas. 1974. A simplified method for cyanogen bromide activation of agarose for affinity chromatography. Anal. Biochem. 60: 149152.

20. Broxmeyer, H. E., A. Smithyman, R. R. Eger, P. A. Meyers, and M. deSousa. 1978. Identification of lactoferrin as the granulocyte-derived inhibitor of colony stimulating activity production. J. Exp. Med. 148: 1052-1067.

21. Masson, P. L., and J. F. Heremans. 1968. Metal combining properties of human lactoferrin (red milk protein). 1 . The involvement of bicarbonate in the reaction. Eur. J. Biochem. 6: 579-584.

22. Bennett, R. M., and T. Kokocinski. 1978. Lactoferrin content of peripheral blood cells. Br. J. Haematol. 39: $509-521$.
23. Aisen, P., R. Aasa, B. G. Malmström, and T. Vänngård. 1967. Bicarbonate and the binding of iron to transferrin. J. Biol. Chem. 242: 2484-2490.

24. Bates, G. W., C. Billups, and P. Saltman. 1967. The kinetics and mechanism of iron (III) exchange between chelates and transferrin. J. Biol. Chem. 242: 2810-2815.

25. Ballentine, R., and D. D. Burford. 1957. Determination of metals. In Methods in Enzymology. S. P. Colowick and N. O. Kaplan, editors. Academic Press Inc., New York. III: $1017-1035$

26. Ambruso, D. R., K. M. Altenburger, and R. B. Johnston, Jr. 1979. Defective oxidative metabolism in newborn neutrophils: discrepancy between superoxide anion and hydroxyl radical generation. Pediatrics. 64: 722-725.

27. Dorfman, L. M., and G. E. Adams. 1973. Reactivity of the hydroxyl radical in aqueous solutions. National Standard Reference Data System-National Bureau of Standards. No. 46. U. S. Department of Commerce.

28. Cohen, G. 1978. The generation of hydroxyl radical in biologic systems: toxicological aspects. Photochem. Photobiol. 28: 669-675.

29. Bors, W., E. Lengfeld, M. Saran, C. Fuchs, and C. Michel. 1976. Reactions of oxygen radical species with metnional: a pulse radiolysis study. Biochem. Biophys. Res. Commun. 70: 81-87.

30. Spiro, T. G. 1977. Chemistry and biochemistry of iron. In Proteins of Iron Metabolism. E. B. Brown, P. Aisen, J. Fielding, and R. R. Crichton, editors. Grune and Stratton, New York. xxiii-xxxi.

31. Propper, R. D., S. B. Shurin, and D. G. Nathan. 1975. Desferrioxamine B and iron overload. In Proceedings of a Symposium on the Development of Iron Chelators for Clinical Use. W. F. Anderson and M. C. Hiller, editors. Department of Health, Education, and Welfare publication, No. (National Institutes of Health) 77994. 83- 122 .

32. Harrison, P. M. 1977. Ferritin: An iron storage molecule. Semin. Hematol. 14: 55-70.

33. Halliwell, B. 1978. Superoxide-dependent formation of hydroxyl radicals in the presence of iron salts. Its role in degradation of hyaluronic acid by a superoxide generating system. FEBS (Fed. Eur. Biochem. Soc.) Lett. 96: 238-242.

34. Oberly, L. W., and G. R. Beuttner. 1979. The production of hydroxyl radical by bleomycin and iron (III). FEBS (Fed. Eur. Biochem. Soc.) Lett. 97: 47-49.

35. Aisen, P. 1973. The transferrins (siderophilins). In Inorganic Biochemistry. G. Eichorn, editor. Elsevier Press, New York. 1: 280-304.

36. Groves, M. L. 1960 . The isolation of a red protein from milk. Am. Chem. Soc. 82: 3345-3350.

37. Montreuil, J., J. Tonnelat, and S. Mullet. 1960. Préparation et propriétés de la lactosidérophiline (lactotransferrine) du lait de femme. Biochem. Biophys. Acta. 45: 413-421.

38. Baggiolini, M., C. deDuve, P. L. Masson, and J. F. Heremans. 1970. Association of lactoferrin with specific granules in rabbit heterophil leukocytes. J. Exp. Med. 131: 559-570.

39. Spitznagel, J. K., F. G. Dalldorf, M. S. Lefell, J. D. Folds, I. R. H. Welsh, M. H. Cooney, and L. E. Martin. 1974. Character of azurophil and specific granules purified from human polymorphonuclear leukocytes. Lab. Invest. 30: 774-785.

40. Spitznagel, J. K., and M. S. Lefell. 1974. Intracellular and extracellular degranulation of human polymorphonuclear azurophil and specific granules induced by immune complexes. Infect. Immun. 10: 1241-1249. 
41. Spitznagel, J. K., M. R. Cooper, A. E. McCall, L. R. DeChatelet, and I. R. H. Welsh. 1972. Selective deficiency of granules associated with lysozyme and lactoferrin in human polymorphs (PMN) with reduced microbicidal activity. J. Clin. Invest. 51: 93a. (Abstr.)

42. Strauss, R. G., K. E. Bove, J. F. Jones, A. M. Mauer, and V. A. Fulginiti. 1974. An anomaly of neutrophil morphology with impaired function. N. Engl. J. Med. 290: 478-484.

43. Komiyama, A., H. Morosawa, T. Nakahata, Y. Miyagawa, and T. Akabane. 1979. Abnormal neutrophil maturation in a neutrophil defect with morphologic abnormality and impaired function. J. Pediatr. 94: 19-25.

44. Parmley, R. T., M. Ogawa, C. P. Darby, Jr., and S. S. Spicer. 1975. Congenital neutropenia: neutrophil proliferation with abnormal maturation. Blood. 46: 723-734.

45. Breton-Gorius, J., D. Y. Mason, D. Buriot, J. L. Vilde, and C. Griscelli. 1980. Lactoferrin deficiency as a consequence of a lack of specific granules in neutrophils from a patient with recurrent infections. Am. J. Pathol. 99: 413-420.

46. Wang-Iverson, P., K. B. Pryzwanski, J. K. Spitznagel, and M. H. Cooney. 1978. Bactericidal capacity of phorbol myristate acetate-treated human polymorphonuclear leukocytes. Infect. Immunol. 22: 945-955.
47. Malmquist, J., J. I. Thorell, and F. A. Wollheim. 1977. Lactoferrin and lysozyme in arthritic exudates. Acta Med. Scand. 202: 313-318.

48. Zebrak, J., T. Herman, R. Werys, J. Pryjma, and J. Gawel 1979. Proteins in bronchial secretion of children with chronic pulmonary disease. II. Relation to bronchoscopic and bronchographic examination. Scand. J. Respir. Dis. 60: $69-75$.

49. Sacks, T., C. F. Moldow, P. R. Craddock, T. K. Bowers, and H. S. Jacob. 1978. Oxygen radicals mediate endothelial cell damage by complement-stimulated granulocytes. An in vitro model of immune vascular damage. J. Clin. Invest. 61: 1161-1167.

50. Chang, Y. H. 1969. Studies on phagocytosis: I. uptake of radio-iodinated $\left({ }^{131} \mathrm{I}\right)$ human serum albumin as a measure of the degree of phagocytosis in vitro. Exp. Cell Res. 54: $42-48$

51. Lestas, A. N. 1976. The effect of $\mathrm{pH}$ upon human transferrin: selective labeling of the two iron binding sites. Br. J. Haematol. 32: 341-350.

52. Repine, J. E., E. M. Berger, and R. B. Fox. 1980. Killing of Staphylococcus aureus by human neutrophils involves hydroxyl radical $(\cdot \mathrm{OH}): \cdot \mathrm{OH}$ may be made by $\mathrm{PMN}$ or reaction of hydrogen peroxide with bacterial iron. Clin. Res. 28: 514a. (Abstr.) 